\title{
p53 positively regulates the expression of cancer stem cell marker CD133 in HCT116 colon cancer cells
}

\author{
XIA CHEN $^{1,2}$, HUA GUAN ${ }^{2}$, XIAO-DAN LIU ${ }^{2}$, DA-FEI XIE ${ }^{2}$, YU WANG $^{2}$, \\ TENG MA ${ }^{2}$, BO HUANG $^{1}$ and PING-KUN ZHOU ${ }^{1,2}$ \\ ${ }^{1}$ Institute for Environmental Medicine and Radiation Hygiene, School of Public Health, University of \\ South China, Hengyang, Hunan 421001; ${ }^{2}$ Department of Radiation Toxicology and Oncology, \\ Beijing Key Laboratory for Radiobiology, Beijing Institute of Radiation Medicine, Beijing 100850, P.R. China
}

Received August 20, 2017; Accepted November 16, 2017

DOI: $10.3892 / \mathrm{ol} .2018 .8619$

\begin{abstract}
Colon cancer stem cells (CSCs), which are highly capable of self-renewal and proliferation, are involved in colon tumorigenesis and response to therapy. CD133 is considered the most robust surface marker for colorectal cancer stem cells. Although the TP53 gene is frequently mutated in colon cancer, it remains not fully understood whether and how tumor protein p53 (p53) is associated with CD133 expression in colon cancer cells. In the present study, the expression of the CSC biomarker CD133 was investigated in terms of p53 status in colorectal carcinoma HCT116 cells. p53 wild-type HCT116 (HCT116 p53 ${ }^{+/+}$) and depleted HCT116 (HCT116 p53 ${ }^{-/}$) cells were used throughout this study. Cells carrying the CSC biomarkers CD133 and CD44 were examined by flow cytometry. A dual-luciferase reporter assay was employed to further confirm the transcriptional regulation of the CD133 promoter by $\mathrm{p} 53$. The results demonstrated that there was a significant difference in the \% of CD133-positive cells between the HCT116 p53 ${ }^{+/+}$cell line $(84.84 \pm 0.05 \%)$ and the HCT116 p53 cell line $(4.13 \pm 0.02 \%)$. The mRNA expression levels of CD133 in HCT116 p53 ${ }^{+/+}$cells were also significantly higher compared with HCT116 p53 $^{--}$cells. Knockdown of p53 by specific small interfering RNA greatly reduced the expression of CD133 in

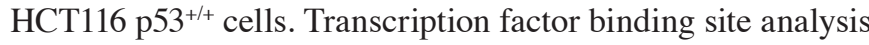
indicated that there are several p53 binding elements in the
\end{abstract}

Correspondence to: Professor Ping-Kun Zhou, Department of Radiation Toxicology and Oncology, Beijing Key Laboratory for Radiobiology, Beijing Institute of Radiation Medicine, 27 Taiping Road, Beijing 100850, P.R. China

E-mail: zhoupk@bmi.ac.cn

Dr Bo Huang, Institute for Environmental Medicine and Radiation Hygiene, School of Public Health, University of South China, Hengyang, 28 Changsheng West Road, Hengyang, Hunan 421001, P.R. China

E-mail: huangbo0930@163.com

Key words: cancer stem cell, CD133, tumor protein p53, promoter, gene expression, colorectal cancer
CD133 promoter region. A dual-luciferase reporter assay further demonstrated the transcriptional activation of CD133 promoter by $\mathrm{p} 53$. In conclusion, these results suggest that $\mathrm{p} 53$ positively regulates the expression of CSC marker CD133 in the HCT116 human colon colorectal cancer cell line. p53 may be involved in the initiation and maintenance of colorectal cancer stem cells through regulating the expression of CD133.

\section{Introduction}

Colorectal carcinoma (CRC), which is prone to metastasis and recurrence, is a cancer with a high lethality rate worldwide. More than $50 \%$ of patients will develop metastasis and recurrence $(1,2)$. Multiple factors account for metastasis and recurrence, including tumor stage, cancer subtypes and cancer stem cells (CSCs). CSCs are a small population of tumor-initiating cells that have the ability to self-renew and differentiate in tumors in vivo. CSCs are involved in various processes during tumor formation, progression, and angiogenesis and are considered an important target for novel cancer treatment strategies (3). Several specific surface markers are expressed on CSCs, including CD133, CD44 and aldehyde dehydrogenase 1 (ALDH1) (4). CD133 (also known as prominin-1) is a 5-transmembrane glycoprotein of 865 amino acids with a total molecular weight of $120 \mathrm{kDa}$. CD133 is a CSC marker in colon carcinoma. CD133-positive cells correlate strongly with poor prognosis and synchronous liver metastasis (5). Cancer cell populations with high expression of CD133 are much more aggressive in terms of metastases compared with those with low expression of CD133, suggesting that CD133 may be a marker of increased tumorigenesis ability. CD133-positive cells from clinical biopsy-derived cultures have been demonstrated to possess multilineage differentiation potential and are capable of tumor initiation in vivo. CD133-positive CRC cells are more resistant to chemoradiotherapy, and CD133 expression is associated with poor prognosis $(6,7)$. However, the regulation of CD133 expression has not been fully elucidated.

The present study demonstrated that CD133 expression was associated with the tumor protein p53 (p53) expression in an HCT116 p53 $^{+/+}$cell line. Of note, CD133-negative cells were detected in the colon cancer cell line HCT116 in a previous report by Kai et al (8). Although the p53 status of the HCT116 
cell line was not mentioned in that previous study (8), it was speculated that an association of CD133 expression with p53 may be possible. Therefore, the present study focused on CD133 in HCT116 cell lines exhibiting different p53 expression status.

Wild-type p53 functions as a bona fide tumor suppressor gene that is involved in transcription, DNA replication and repair, cell cycle arrest, proliferation, apoptosis, angiogenesis inhibition, and cellular stress responses. Various types of cancer harbor p53 mutations. In specific, $>50 \%$ of colon cancers contain p53 mutations $(9,10)$. p53 is known to regulate the balance of asymmetric and symmetric divisions of stem cells. A broken balance of asymmetric and symmetric cell division leads to either tumor suppression or tumor expansion.

In the present study, CSC subpopulation distributions, marked by CD133 and CD44 expression, were significantly different in HCT116 p53 ${ }^{+/+}$and HCT116 p53/- cell lines. Therefore, the hypothesis that there may be a functional interaction between the CSC biomarker CD133 and p53 was examined.

\section{Materials and methods}

Cell culture. The human colon cancer cell lines HCT116 p53 and HCT116 p53-- were well-established cell lines (11), kindly provided by Professor Xingzhi Xu (College of Life Sciences, Capital Normal University, Beijing, China) and maintained in our laboratory. All HCT116 cells were cultured in McCoy's 5A medium (HyClone; GE Healthcare Life Sciences, Logan, UT, USA). The human embryo kidney epithelial cell line 393T (cat. no. CL00022; Fengh Bio, Changsha, China) was cultured in Dulbecco's Modified Essential Medium (HyClone; GE Healthcare Life Sciences), supplemented with $10 \%$ fetal bovine serum (HyClone; GE Healthcare Life Sciences), $100 \mathrm{U} / \mathrm{ml}$ penicillin and $100 \mu \mathrm{g} / \mathrm{ml}$ streptomycin (both from Invitrogen; Thermo Fisher Scientific, Inc., Waltham, MA, USA) in a humidified atmosphere with $5 \% \mathrm{CO}_{2}$ and incubated at $37^{\circ} \mathrm{C}$.

Flow cytometric analysis. To harvest the cell samples, the cultured cells were incubated with $0.25 \%$ trypsin for $90 \mathrm{sec}$, collected and washed with cold PBS. The cell suspension was centrifuged at $300 \mathrm{x}$ g for $10 \mathrm{~min}$ at room temperature, and the supernatant was discarded. The cells were resuspended in buffer containing PBS ( $\mathrm{pH} 7.2$ ), $0.5 \%$ bovine serum albumin (BSA), and $2 \mathrm{mM}$ EDTA. Next, $10 \mu \mathrm{l}$ of the CD133/1 (AC133)-fluorescein isothiocyanate (FITC) antibody (clone, 393C3, cat. no. 130-104-322) and $10 \mu \mathrm{l}$ of the CD44-phycoerythrin (PE) antibody (clone DB105, cat. no. 130-098-108) (both from Miltenyi Biotec, $\mathrm{GmbH}$, Bergisch, Germany) were added, mixed well and incubated for $10 \mathrm{~min}$ in the dark at $4^{\circ} \mathrm{C}$. Then, the cells were washed with 1-2 ml buffer and centrifuged at $300 \mathrm{x}$ g for $10 \mathrm{~min}$ at room temperature. Finally, the cell pellets were resuspended in $1 \%$ triformol for analysis by flow cytometry using the BD FACSDiva software version 7.0 (BD Biosciences, Franklin Lakes, NJ, USA).

Western blot analysis. Cells were harvested at different times, from 0 to $24 \mathrm{~h}$. After the medium was discarded, cells were washed with ice-cold PBS twice and trypsinized on ice for $30 \mathrm{~min}$. Cells lysates were prepared with M-PER ${ }^{\mathrm{TM}}$ cell lysis buffer (cat. no. 78501; Thermo Fisher Scientific, Waltham, MA, USA) at $4^{\circ} \mathrm{C}$ for $30 \mathrm{~min}$, and then centrifuged at $11,500 \mathrm{x} \mathrm{g}$ for 15 min at $4^{\circ} \mathrm{C}$. The protein concentration was measured by bicinchoninic acid protein assay, and A280 absorption was measured using a NanoDrop 2000c/2000 (Thermo Fisher Scientific, Inc.). A total of $40 \mu \mathrm{g}$ protein extract was loaded onto a $10 \%$ SDS polyacrylamide gel. Following electrophoresis, proteins were transferred to polyvinylidene difluoride membranes (Bio-Rad Laboratories, Inc., Hercules, CA, USA) and incubated with the indicated primary antibodies: Mouse anti-p53 (cat. no. ab1101, Abcam; Cambridge, UK) or mouse anti-GAPDH (cat. no. ab9485; Abcam) at a dilution of 1:1,000 at $4{ }^{\circ} \mathrm{C}$ overnight. Then, the blots were incubated with a secondary horseradish peroxidase-conjugated goat anti-mouse antibody (dilution 1:2,000; cat. no. sc-2005; Santa Cruz Biotechnology, Inc., Dallas, TX, USA) at room temperature for $1 \mathrm{~h}$. The protein signal was visualized using an enhanced chemiluminescence detection kit (Thermo Fisher Scientific, Inc.).

Reverse transcription-quantitative polymerase chain reaction $(R T-q P C R)$. For detecting the CD133 mRNA expression levels in HCT116 p53 $3^{+/+}$cells and HCT116 $\mathrm{p} 53^{-/-}$cells, total RNA was isolated with the TRIzol regent and treated with RNase-free DNase (both from Thermo Fisher Scientific, Inc.), and reverse transcribed into cDNA using ReverTraAce ${ }^{\circledR} \mathrm{qPCR}$ RTMaster (Toyobo Life Science, Osaka, Japan). qPCR was performed using a DyNAmo ColorFlash SYBR Green qPCR kit (Thermo Fisher Scientific, Inc.), according to the manufacturer's instructions. The primers used were as follows: CD133 forward, 5'-GATTCATACTGGTGGCTGGGTGG-3' and reverse, 5'-GCAGGTGAAGAGTGCCGTAAGT-3'; and $\beta$-actin forward, 5'-TTGAAGGTAGTTTCGTGGAT-3' and reverse, 5'-ATCACCATTGGCAATGAGCG-3'. The thermocycling conditions for the qPCR were as follows: $95^{\circ} \mathrm{C}$ for $2 \mathrm{~min}$, followed by 39 cycles of $95^{\circ} \mathrm{C}$ for $30 \mathrm{sec}$ and $60^{\circ} \mathrm{C}$ for $30 \mathrm{sec}$, and finally $1 \mathrm{~min}$ at $68^{\circ} \mathrm{C}$. Relative fold changes in mRNA expression were calculated using the formula $2^{-\Delta \Delta \mathrm{Cq}}(12)$.

CD133 promoter analysis. The CD133 promoter sequence (sequence ID, AY275524; obtained from http://www.genecopoeia.com/; target gene accession: NM_006017) was analyzed using a web-based prediction tool (http://tfbind.hgc.jp/). p53 was identified as one transcription factor that may interact with the CD133 promoter sequence.

siRNA and plasmid transfection. p53 siRNA oligonucleotides were from Taihe Biotechnology Co., Ltd. (Beijing, China) with a sense strand sequence of: 5'ATGGATCCGTGACAC GCTTCCCTGGATTG3'. The control siRNA (cat. no. B01001) was purchased from GenePharma Co., Ltd. (Shanghai, China) and Flag-cmv2-p53 (GenePharma Co., Ltd., Shanghai, China) transfections, $1 \times 10^{6} \mathrm{HCT} 116 \mathrm{p} 53^{+/+}$or HCT116 $\mathrm{p} 53^{-/-}$cells, respectively, were plated in $60 \mathrm{~mm}$ dishes for transfection the following day. After $24 \mathrm{~h}$, cells were transfected with $660 \mathrm{pmol}$ p53 siRNA or $2 \mu \mathrm{g}$ Flag-cmv2-p53 plasmid or its negative control Flag-cmv2 plasmid, using Lipofectamine 2000 (Thermo Fisher Scientific, Inc.), following the manufacturer's instructions.

Dual-luciferase reporter assay. To measure the effect of p53 on the CD133 promoter activity, the Promega dual-luciferase reporter assay system (cat. no. E1910; Promega Corporation, Madison, WI, USA) was used, according to the manufacturer's 
A

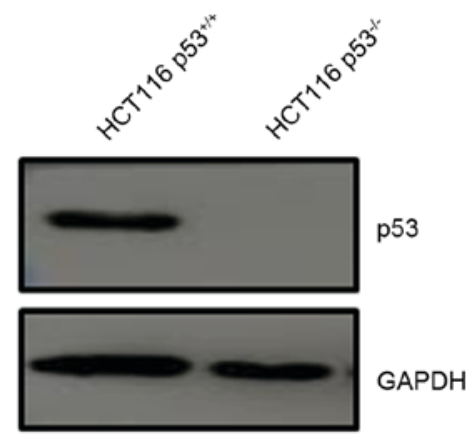

C

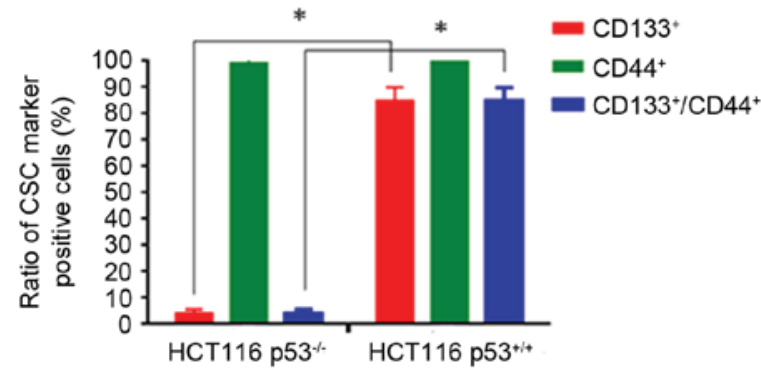

B
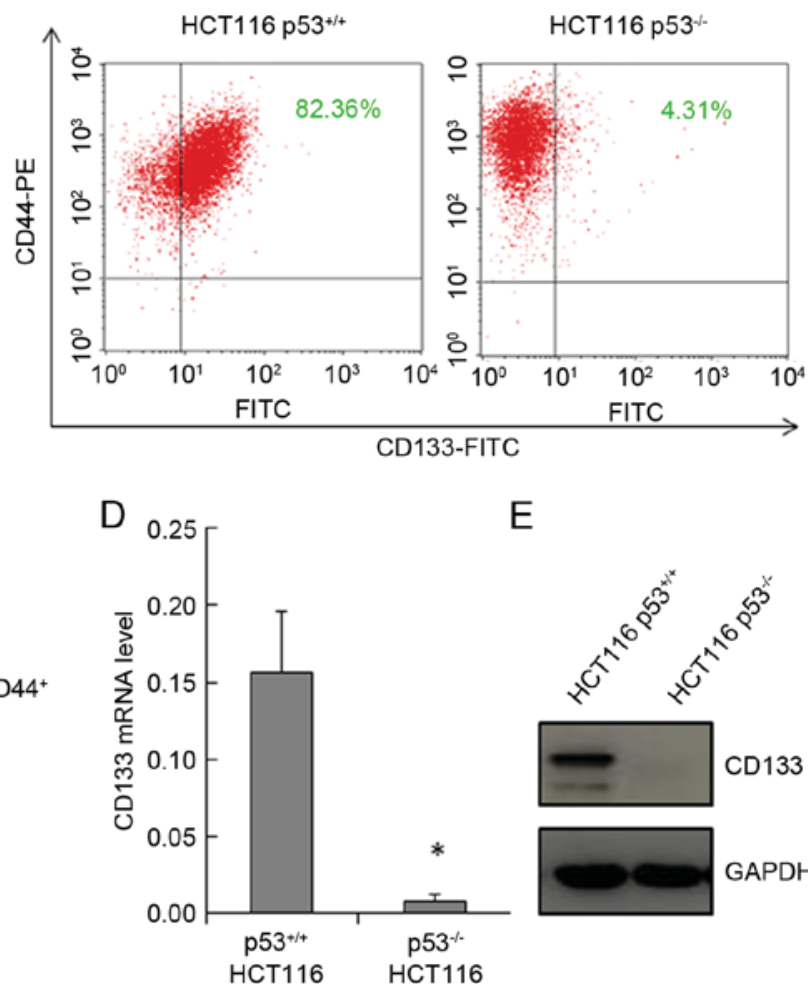

E

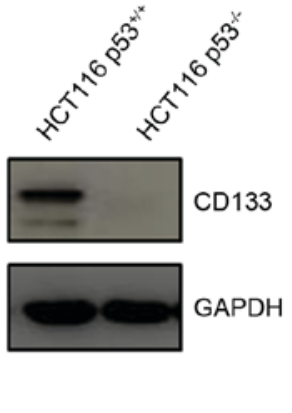

Figure 1. Differential expression of the CSC surface marker CD133 in p53 $3^{+/+}$and $\mathrm{p} 53^{-/-}$HCT116 cell lines. (A) Western blot analysis of p53 expression in HCT116 cell lines. (B) Flow cytometric analysis of CD133 and CD44 expression in p53 $3^{+/+}$and p53 $3^{-/}$HCT116 cell lines. (C) Quantification of flow cytometry results for CD133 and CD44 expression in the two HCT116 cell lines. ${ }^{~} \mathrm{P}<0.01$, with comparisons indicated by brackets. (D) CD133 mRNA expression levels in $\mathrm{p} 53^{+/+}$and $\mathrm{p} 53^{-/} \mathrm{HCT} 116$ cell lines were detected by reverse transcription-quantitative polymerase chain reaction. ${ }^{*} \mathrm{P}<0.01$ for $\mathrm{p} 53^{+/ /} \mathrm{vs}$. $\mathrm{p} 53^{-/-} \mathrm{HCT} 116$ cells. (E) Western blot analysis of CD133 protein expression. CSC, cancer stem cell; PE, phycoerythrin; FITC, fluorescein isothiocyanate.

instructions. HCT116 p53 $3^{+/+}$cells were co-transfected with $0.8 \mu \mathrm{g}$ pGL3-pCD133 reporter vector or pGL3-basic control and $8 \mathrm{ng}$ pRL-CMV vector, and simultaneously transfected with 660 pmol p53 siRNA or control siRNA. HCT116 p53-1cells were co-transfected with $0.8 \mu \mathrm{g}$ pGL3-pCD133 reporter vector or pGL3-basic control and $8 \mathrm{ng}$ pRL-CMV vector, and simultaneously transfected with $1 \mu \mathrm{g}$ Flag-cmv2-p53 vector or control. Expression of p53 protein and CD133 promoter activity were analyzed $24 \mathrm{~h}$ post-transfection. $293 \mathrm{~T}$ cells were transfected exactly as described for the HCT116 cells. Transfections were performed using Lipofectamine 2000 (Thermo Fisher Scientific, Inc.), according to manufacturer's instructions. Cells were harvested $24 \mathrm{~h}$ post-transfection and plated in 96-well plates. Then, firefly luciferase and Renilla luciferase activity were measured.

Statistical analysis. The graphs were plotted and analyzed using t-test or one-way analysis of variance in GraphPad Prism 6 (GraphPad Software, Inc., La Jolla, CA, USA). P $<0.05$ was considered to indicate a statistically significant difference. All experiments were repeated at least three independent times. The data are presented as the mean \pm standard deviation (SD).

\section{Results}

Distribution of the CD133-positive subpopulation in HCT116 p53 $3^{+/+}$and HCT116 p53/- cell lines. After the p53 status was confirmed in both cell lines (Fig. 1A), flow cytometry was used to analyze CD133/CD44 expression in HCT116 cells. As illustrated in Fig. 1B, the $\mathrm{CD} 133^{+} / \mathrm{CD} 44^{+}$subpopulation in the HCT116 p53 $3^{+/+}$cell line was $84.84 \pm 0.05 \%$ of total cells, while in the HCT116 $553^{-/}$it was $4.13 \pm 0.02 \%$ of total cells. The difference in the CD133-positive CSC subpopulations between the two cell lines was statistically significant $(\mathrm{P}<0.001$; Fig. 1C). However, there was no significant difference in the \% of CD44-positive cell populations between these two cell lines (Fig. 1C). The CD133 mRNA expression levels, as detected by RT-qPCR (Fig. 1D), and the protein expression levels, as detected by western blot analysis (Fig. 1E), were also significantly reduced in HCT116 $\mathrm{p} 53^{-/}$cells compared with

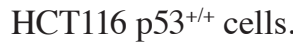

p53 activates CD133 expression. To examine whether p53 could regulate CD133 expression, p53-specific siRNA was used to abrogate p53 expression in HCT116 p53 $3^{+/+}$cells. The western blot analysis and qPCR results confirmed that expression of p53 protein (Fig. 2A) and mRNA (Fig. 2B) was significantly reduced in the HCT116 $\mathrm{p}^{+/+}$cells following transfection with the p53-specific siRNA compared with cells transfected with a negative control siRNA. p21 protein expression was simultaneously decreased following siRNA transfection (Fig. 2A). Knockdown of p53 by siRNA resulted in a significant decrease in CD133-positive cells, from $84.27 \%$ in the control-transfected cells to $5.94 \%$ in the p53-siRNA-transfected HCT116 p53 $3^{+/+}$cells (Fig. 2C). In addition, the CD133 mRNA levels were also decreased following 
A

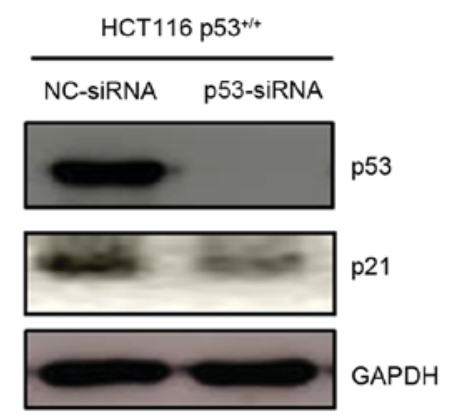

C

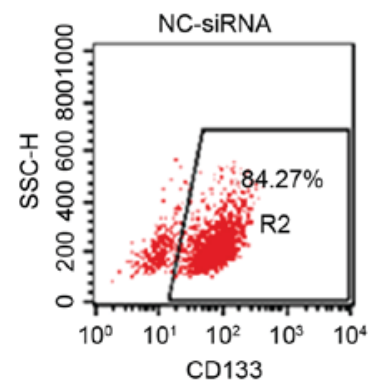

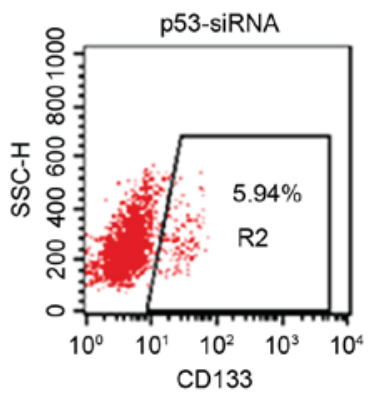

B

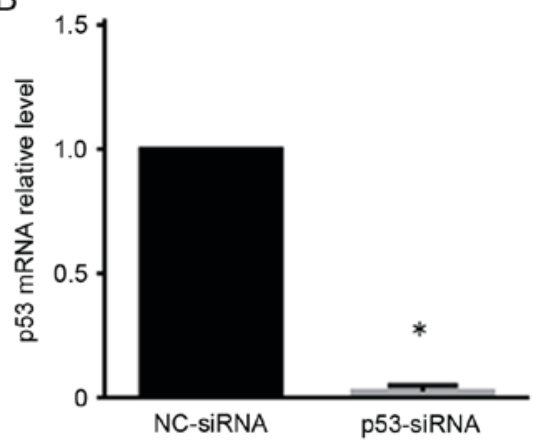

D

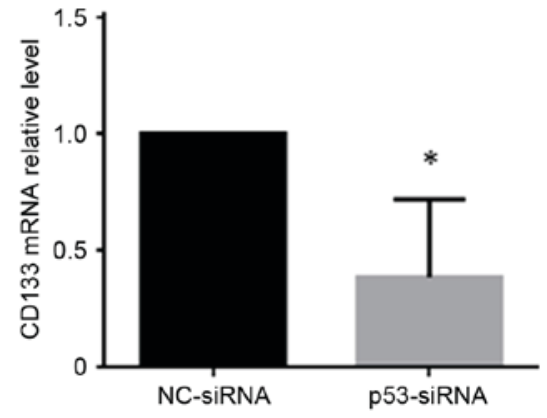

Figure 2. Effect of p53 silencing on CD133 expression in p53 ${ }^{+/+}$HCT116 cells. p53 ${ }^{+/+}$HCT116 cells were transfected with either a p53-specific siRNA or a negative control siRNA (NC). (A) Western blot analysis for p53 and p21 protein expression levels. (B) RT-qPCR analysis for p53 mRNA expression. ${ }^{*} \mathrm{P}<0.01$. (C) Representative results of flow cytometric analysis for expression of the cancer stem cell marker CD113. siRNA-mediated p53 silencing resulted in a decreased $\%$ of CD113-positive cells in the p53 ${ }^{+/+}$HCT116 cell line. (D) RT-qPCR analysis for CD133 mRNA expression. siRNA-mediated p53 silencing resulted in decreased mRNA levels of CD133 in the p53 ${ }^{+/+}$HCT116 cell line. ${ }^{*} \mathrm{P}<0.01$. si, small interfering; NC, negative control; RT-qPCR, reverse transcription-quantitative polymerase chain reaction.

p53 siRNA knockdown (Fig. 2D). These results suggested that p53 might transcriptionally regulate CD133 mRNA expression.

Next, the Flag-cmv2-p53 plasmid was transiently transfected into HCT116 p53 cells in order to overexpress p53 in these cells, while the empty Flag-cmv2 vector was used as control. Western blot analysis demonstrated increased levels of p53 and p21 protein at 24 and 48 h following transfection (Fig. 3A). One-half of the same transfected sample was then used for flow cytometric detection of the CSC surface biomarker CD133. The \% of CD133-positive cells increased from 4.19 to $5.13 \%$ at $24 \mathrm{~h}$ and to $7.25 \%$ at $48 \mathrm{~h}$ following $\mathrm{p} 53$ overexpression (Fig. 3B). Although the increase in overall \% is relatively small, the change is statistically significant (Fig. 3C). In addition, the qPCR results indicated that CD133 mRNA levels were significantly increased in $\mathrm{HCT} 116 \mathrm{p} 53^{-/}$cells following p53 overexpression (Fig. 3D).

Prediction of p53 response elements in the CD133 promoter. DNA binding is necessary for p53 transcription factor activity. p53 modulates the transcription of target genes mainly through its direct binding to a specific responsive element (RE), usually within the promoter region of its target genes. The consensus sequence of the p53 binding site is 5'-RRRCWWGYYY-3', where $\mathrm{R}$ is a purine, $\mathrm{Y}$ is a pyrimidine, and $\mathrm{W}$ is either adenine (A) or (thymine) $\mathrm{T}$ (13). Fig. 4A displays the consensus p53 RE sequence Model logo MA0106 generated using the LogoMat-M software (http://www.sanger.ac.uk/science/tools/logomat-m) (14). The
Multi-genome Analysis of Positions and Patterns of Elements of Regulation (MAPPER) Search Engine (15) was used to identify the putative p53 binding sites/ REs in the promoter of the human CD133/PROM1 gene. Using the MAPPER Search Engine, the promoter sequence of the human CD133 gene from the National Center for Biotechnology Information (NCBI) GenBank genome database (NCBI reference sequence: NG_011696.1) was queried. Indeed, the sequence alignment revealed three potential p53 REs at -1222/-1213, -387/-368 and $-285 /-266$ within the $1.5 \mathrm{~kb}$ region of the CD133 gene promoter (Fig. 4B).

p53 transactivates the CD133 promoter. To investigate whether p53 transactivates the CD133 promoter, the sequence 1,313 bp upstream of the CD133 promoter, containing these three potential p53 REs, was cloned into a luciferase reporter plasmid (pGL3-pCD133), thereby producing a plasmid where the firefly luciferase gene expression is driven by the CD133 promoter (Fig. 4C). The cells were co-transfected with the firefly luciferase reporter pGL3-pCD133 plasmid, the pRL-CMV plasmid (which expresses Renilla luciferase as the internal control), and other plasmids as indicated. The empty pGL3-basic vector was transfected as a control. As presented in Fig. 5A and B, siRNA-mediated silencing of p53 resulted in a significant decrease in firefly luciferase activity in $\mathrm{p}^{+/+}$HCT116 cells. By contrast, overexpression of 53 by co-transfection of the p53-expressing vector pCMV2-p53 significantly increased the firefly luciferase activity in $\mathrm{p} 53^{-1-}$ HCT116 cells (Fig. 5C and D). These results suggest that p53 
A

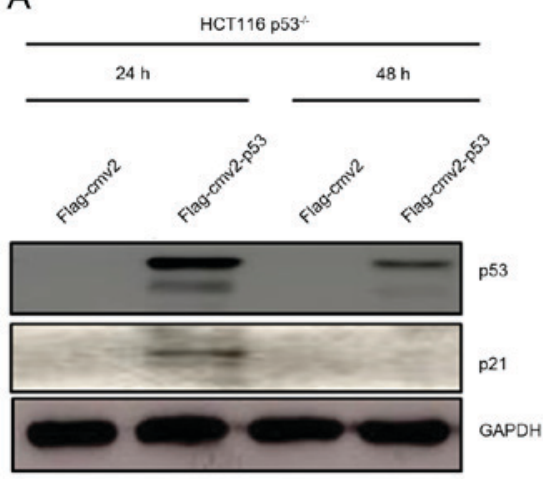

C

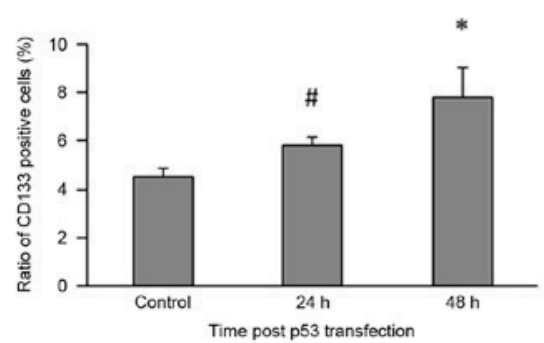

B
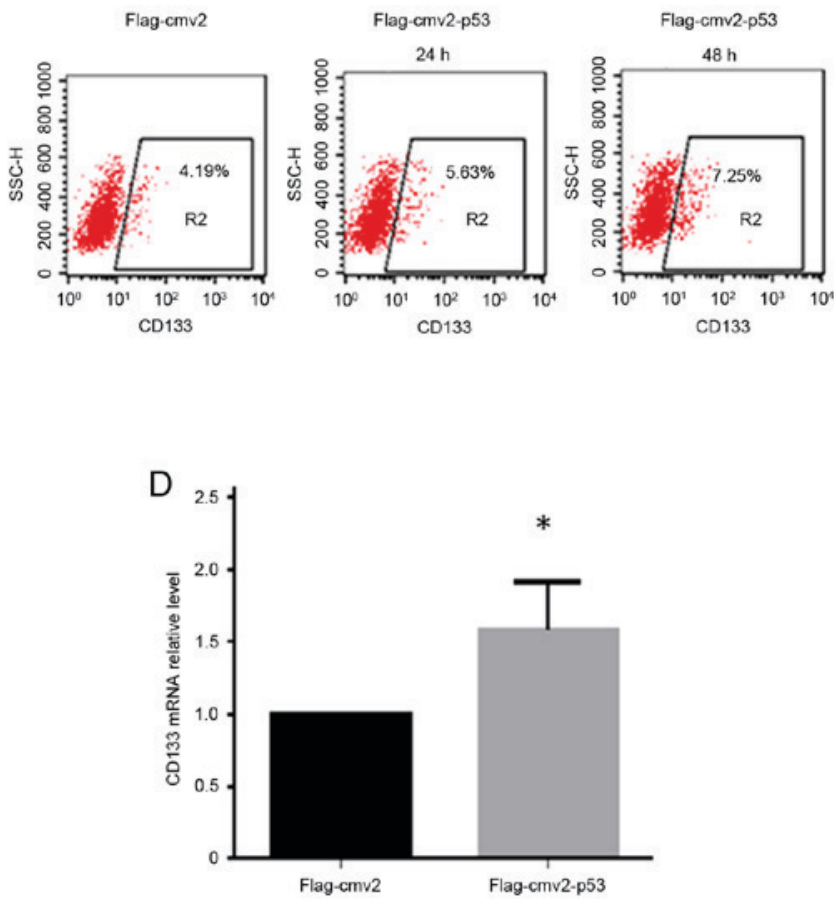

Figure 3. Effect of p53 overexpression on CD133 expression in p53 ${ }^{-/-}$HCT116 cells. p53 ${ }^{-/}$HCT116 cells were transfected with either a p53-overexpressing plasmid (Flag-cmv2-p53) or the empty vector control (Flag-cmv2). (A) Western blot analysis for p53 and p21 protein expression levels. (B) Representative results of flow cytometric analysis for expression of the cancer stem cell marker CD113. (C) Quantitative analysis of the flow cytometry results for the \% of CD113-positive cells in total. " $\mathrm{P}<0.05$ and ${ }^{*} \mathrm{P}<0.01$ compared with the control. (D) Reverse transcription-quantitative polymerase chain reaction analysis for CD133 mRNA expression. p53 overexpression resulted in increased CD133 mRNA levels in p53 ${ }^{-/}$HCT116 cells. * $<<0.01$ compared with the control.

A

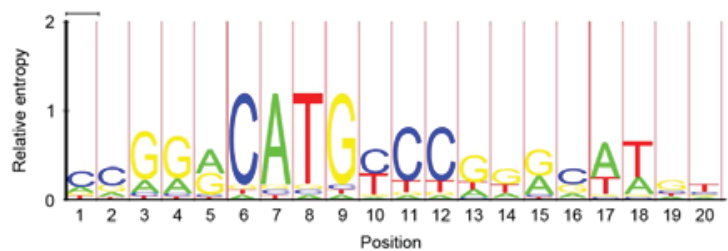

B

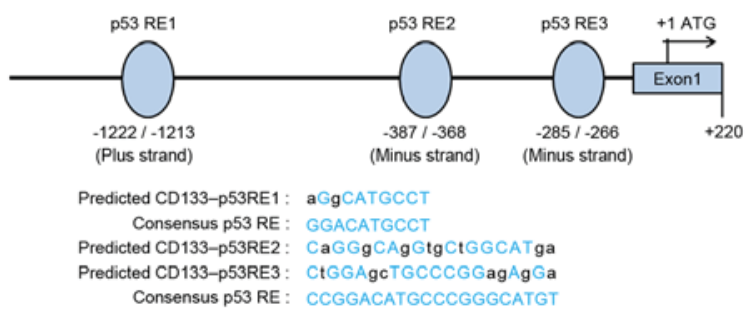

C

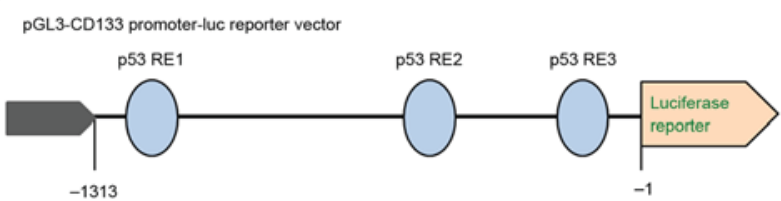

Figure 4. Prediction of p53 REs in the CD133 promoter. (A) Model logo MA0106 of the consensus p53 RE sequence generated using the LogoMat-M software. (B) Positions and sequences of the predicted p53 REs within the CD133 promoter. The location of each p53 RE in the promoter is labeled relative to the transcription start site. (C) Schematic for the construct pGL3-pCD133 promoter-Luc reporter vector that was generated for the present study. The firefly luciferase gene expression is driven by the 1,313 bp CD133 promoter fragment containing the predicted p53 REs. $\mathrm{RE}$, response element. transactivates the CD133 promoter region containing the $\mathrm{p} 53$ REs. Similarly, in 293T cells, siRNA-mediated silencing of p53 significantly decreased luciferase activity, while overexpression of exogenous p53 significantly increased luciferase activity driven from the CD133 promoter, in a concentration-dependent manner (Fig. 5E and F). Therefore, the present results demonstrated that p53 may activate the CD133 promoter.

\section{Discussion}

The present study reported the role of p53 in transcriptionally activating the expression of the cancer stem cell marker CD133. A significant difference in the ratio of CD133-positive cell populations was demonstrated between the HCT116 $\mathrm{p} 53^{+/+}$and $\mathrm{p} 53^{-/}$cell lines. Silencing or overexpression of p53 decreased or restored CD133 expression, respectively. Informatics analysis predicted that a 1,313 bp fragment upstream of the CD133 transcriptional start site contained putative p53 binding REs and a dual-luciferase reporter assay demonstrated that p53 effectively activated transcription from the CD133 promoter region.

CD133 has been reported by several studies as a putative colon cancer stem cell marker $(16,17)$. It has been demonstrated that CD133-positive cells are more resistant to radiation and conventional chemotherapy compared with CD133-negative cells (18). CD133-positive cells exhibit all the traits of stemness, including the ability to self-renew, differentiate and form tumors in immunodeficient mice (19). The expression of CD133 in different colorectal cancer cell 
A

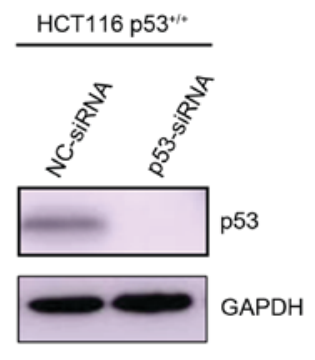

C

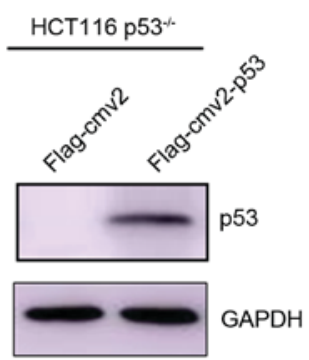

E

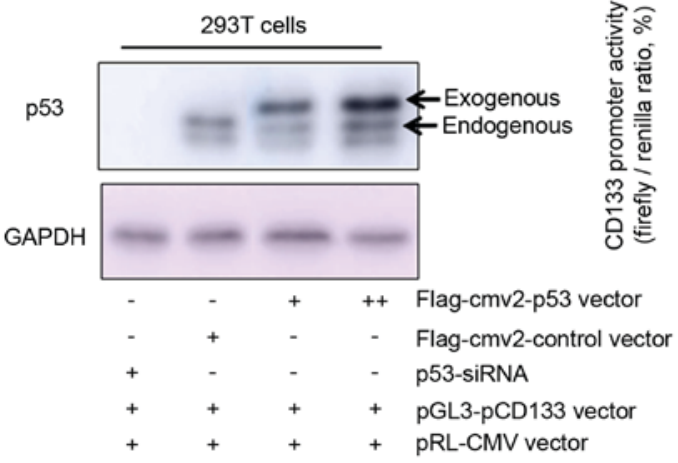

B

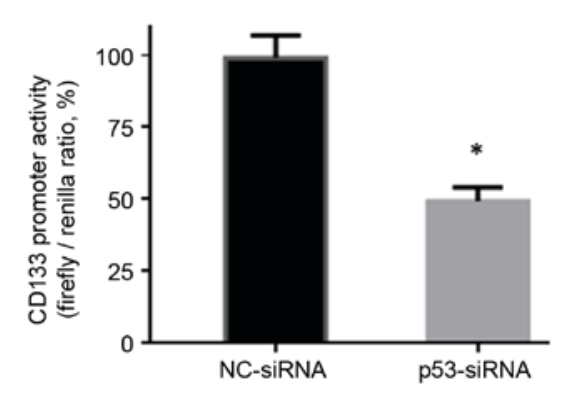

D

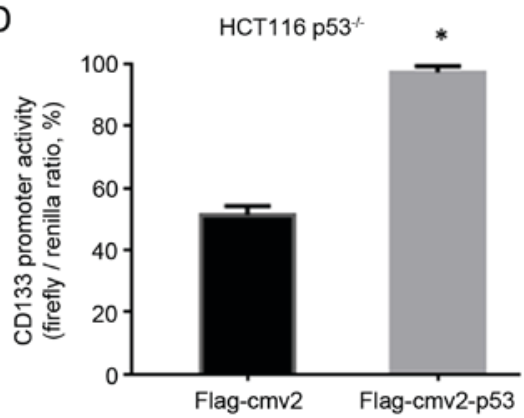

$\mathrm{F}$

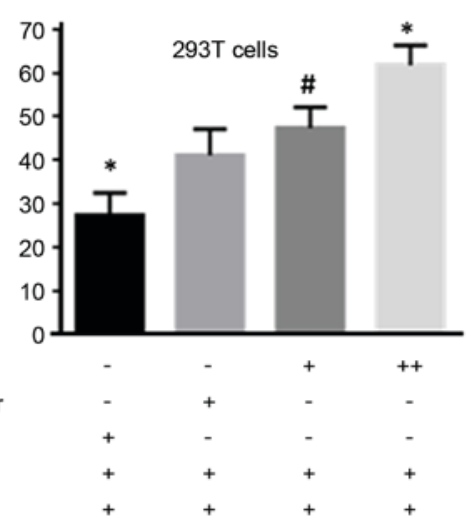

Figure 5. p53 transactivates the CD133 promoter. (A) Western blot analysis of p53 protein expression following p53-specific siRNA knockdown in p53 $3^{+/+}$ HCT116 cells. (B) p53 knockdown suppressed the activity of the CD133 promoter in p53 ${ }^{+/+}$HCT116 cells, as measured by a dual-luciferase reporter assay. CD133 promoter activity was expressed as the ratio of firefly/Renilla luciferase activity. "P<0.01 compared with control. (C) Western blot analysis of p53 expression following transfection of p53 $3^{-/} \mathrm{HCT} 116$ cells with either a p53-overexpressing plasmid (Flag-cmv2-p53) or the empty vector control (Flag-cmv2). (D) 553 overexpression increased the activity of the CD133 promoter in $\mathrm{p} 53^{+/+} \mathrm{HCT} 116$ cells, as measured by a dual-luciferase reporter assay. CD133 promoter activity was expressed as the ratio of firefly/Renilla luciferase activity. ${ }^{*} \mathrm{P}<0.01$ compared with control. (E and F) 293T cells were co-transfected with the indicated plasmids and (E) expression of $\mathrm{p} 53$ protein and $(\mathrm{F})$ activity of the $\mathrm{CD} 133$ promoter were analyzed 24 post-transfection, as described earlier. ${ }^{~} \mathrm{P}<0.05$ and ${ }^{*} \mathrm{P}<0.01$, compared with control. si, small interfering; $\mathrm{NC}$, negative control.

lines varies. Chen et al (20) and Yang et al (21) also found that highly enriched CD133-positive cells existed in the HCT116 cell line and that these cells had characteristics of stem cells. Their findings are in accordance with the present results, in which a high population of $\mathrm{CD} 133^{+} / \mathrm{CD} 44^{+}$cells were present in the HCT116 $\mathrm{p}^{+/ /+}$cell line, which is poorly differentiated (22). Multiple studies have reported that different transcription factors are involved in the regulation of CD133 expression, including Notch1, signal transducer and activator of transcription 3, and hypoxia inducible factor (23-30). DNA methylation and epigenetic factors are also involved in CD133 expression regulation (31). However, little is known about how $\mathrm{CD} 133$ is regulated in colon cancer.

Surprisingly, the present results demonstrated that CD133 expression was almost abolished in the HCT116 p53 $3^{-/-}$cells. p53 is one of the central regulators involved in various biological activities, such as transcription, DNA damage response, metabolism and stem cell maintenance (32). Although several studies have indicated that p53 may be involved in the regulation of colon cancer stem cells $(33,34)$, the precise mechanisms are relatively unclear. The present study demonstrated that wild-type 553 transactivated the promoter of the CD133 gene, indicating that the CD133 gene may be a novel target of p53 in colorectal cancer. Although it was previously reported that p53 transcriptionally suppressed CD133 expression (35), p53 may function with different transcription factors in the context of colorectal cancer to maintain the stem cell properties of HCT116 cells, which may be independent of the tumor suppressor role of $\mathrm{p} 53$ in other types of cancer. The specificity and robustness of CD133 as a colorectal CSC marker may 
also need further investigation $(36,37)$. The combinatorial use of other markers, such as CD44 and ALDH1, in colorectal cancers may better clarify CSC features and how p53 may affect stem cell characteristics of colorectal cancer (38).

It is well-acknowledged that p53 transactivates its target genes through binding to a consensus RE (39-44). However, the mechanism by which p53 elicits cell-type specific responses is not fully understood. A previous study has examined the different binding modes of p53 between HCT116 and IMR90 cells (45). It will be interesting to identify other binding sites of p53 in addition to the $1,313 \mathrm{bp}$ fragment upstream of the CD133 promoter. In the present findings, overexpression of p53 in HCT116 p53 $3^{-1}$ cells increased the $\%$ of CD133-positive cells only moderately, suggesting that other epigenetic machinery may also be involved in the transactivation of CD133 expression by p53 $(31,46)$.

In summary, the present study identified CD133 as a target gene of p53 in colorectal cancer cells. The clinical significance of CD133 in other types of cancer cells is already well established (47-52). Large-scale detection of CD133 expression in clinical colorectal cancer specimens may further evaluate the prognostic value of CD133. The identification of positive regulation of CD133 by p53 may provide new clues for the study of $\mathrm{CSC}$ in specific colorectal cancer subtypes.

\section{Acknowledgements}

This study was supported by the National Key Basic Research Program (973 Program) of MOST, China (grant no. 2015CB910601), and the National Natural Science Foundation of China (grant no. U1432248).

\section{References}

1. Cunningham D, Atkin W, Lenz HJ, Lynch HT, Minsky B, Nordlinger B and Starling N: Colorectal cancer. Lancet 375: 1030-1047, 2010.

2. Kerr D: Clinical development of gene therapy for colorectal cancer. Nat Rev Cancer 3: 615-622, 2003.

3. Dalerba P, Dylla SJ, Park IK, Liu R, Wang X, Cho RW, Hoey T, Gurney A, Huang EH, Simeone DM, et al: Phenotypic characterization of human colorectal cancer stem cells. Proc Natl Acad Sci USA 104: 10158-10163, 2007.

4. Puglisi MA, Tesori V, Lattanzi W, Gasbarrini GB and Gasbarrini A: Colon cancer stem cells: Controversies and perspectives. World J Gastroenterol 19: 2997-3006, 2013.

5. Horst D, Scheel SK, Liebmann S, Neumann J, Maatz S, Kirchner T and Jung A: The cancer stem cell marker CD133 has high prognostic impact but unknown functional relevance for the metastasis of human colon cancer. J Pathol 219: 427-434 2009.

6. Hongo K, Kazama S, Sunami E, Tsuno NH, Takahashi K, Nagawa $\mathrm{H}$ and Kitayama $\mathrm{J}$ : Immunohistochemical detection of CD133 is associated with tumor regression grade after chemoradiotherapy in rectal cancer. Med oncol 29: 2849-2857, 2012.

7. Ying X, Wu J, Meng X, Zuo Y, Xia Q, Chen J, Feng Y, Liu R, Li L and Huang W: AC133 expression associated with poor prognosis in stage II colorectal cancer. Med Oncol 30: 356, 2013.

8. Kai K, Nagano O, Sugihara E, Arima Y, Sampetrean O, Ishimoto $T$, Nakanishi $M$, Ueno NT, Iwase $H$ and Saya $H$ : Maintenance of HCT116 colon cancer cell line conforms to a stochastic model but not a cancer stem cell model. Cancer Sci 100: 2275-2282, 2009.

9. Li XL, Zhou J, Chen ZR and Chng WJ: P53 mutations in colorectal cancer-molecular pathogenesis and pharmacological reactivation. World J Gastroenterol 21: 84-93, 2015.

10. Naccarati A, Polakova V, Pardini B, Vodickova L, Hemminki K, Kumar R and Vodicka P: Mutations and polymorphisms in TP53 gene-an overview on the role in colorectal cancer. Mutagenesis 27: 211-218, 2012.
11. Hall EH, Schoenbach KH and Beebe SJ: Nanosecond pulsed electric fields induce apoptosis in p53-wildtype and p53-null HCT116 colon carcinoma cells. Apoptosis 12: 1721-1731, 2007.

12. Livak KJ and Schmittgen TD: Analysis of relative gene expression data using real-time quantitative PCR and the 2(-Delta Delta C(T)) method. Methods 25: 402-408, 2001.

13. Wang B, Xiao Z and Ren EC: Redefining the $\mathrm{p} 53$ response element. Proc Natl Acad Sci USA 106: 14373-14378, 2009.

14. Schuster-Bockler B, Schultz J and Rahmann S: HMM Logos for visualization of protein families. BMC Bioinformatics 5: 7, 2004.

15. Marinescu VD, Kohane IS and Riva A: MAPPER: A search engine for the computational identification of putative transcription factor binding sites in multiple genomes. BMC Bioinformatics 6: 79, 2005.

16. Ricci-Vitiani L, Lombardi DG, Pilozzi E, Biffoni M, Todaro M, Peschle $\mathrm{C}$ and De Maria R: Identification and expansion of human colon-cancer-initiating cells. Nature 445: 111-115, 2007.

17. O'Brien CA, Pollett A, Gallinger S and Dick JE: A human colon cancer cell capable of initiating tumour growth in immunodeficient mice. Nature 445: 106-110, 2007.

18. Bao S, Wu Q, McLendon RE, Hao Y, Shi Q, Hjelmeland AB, Dewhirst MW, Bigner DD and Rich JN: Glioma stem cells promote radioresistance by preferential activation of the DNA damage response. Nature 444: 756-760, 2006.

19. Wu Y and Wu PY: CD133 as a marker for cancer stem cells: Progresses and concerns. Stem Cells Dev 18: 1127-1134, 2009.

20. Chen KL, Pan F, Jiang H, Chen JF, Pei L, Xie FW and Liang HJ: Highly enriched CD133(+)CD44(+) stem-like cells with CD133(+)CD44 (high) metastatic subset in HCT116 colon cancer cells. Clin Exp Metastasis 28: 751-763, 2011.

21. Yang ZL, Zheng Q, Yan J, Pan Y and Wang ZG: Upregulated CD133 expression in tumorigenesis of colon cancer cells. World J Gastroenterol 17: 932-937, 2011.

22. Chantret I, Barbat A, Dussaulx E, Brattain MG and Zweibaum A: Epithelial polarity, villin expression and enterocytic differentiation of cultured human colon carcinoma cells: A survey of twenty cell lines. Cancer Res 48: 1936-1942, 1988.

23. Konishi H, Asano N, Imatani A, Kimura O, Kondo Y, Jin X, Kanno T, Hatta W, Ara N, Asanuma K, et al: Notch1 directly induced CD133 expression in human diffuse type gastric cancers. Oncotarget 30: 56598-56607, 2016.

24. Matsumoto K, Arao T, Tanaka K, Kaneda H, Kudo K, Fujita Y, Tamura D, Aomatsu K, Tamura T, Yamada Y, et al: mTOR signal and hypoxia-inducible factor-1 alpha regulate CD133 expression in cancer cells. Cancer Res 69: 7160-7164, 2009.

25. Mathieu J, Zhang Z, Zhou W, Wang AJ, Heddleston JM, Pinna CM, Hubaud A, Stadler B, Choi M, Bar M, et al: HIF induces human embryonic stem cell markers in cancer cells. Cancer Res 71: 4640-4652, 2011.

26. Won C, Kim BH, Yi EH, Choi KJ, Kim EK, Jeong JM, Lee JH, Jang JJ, Yoon JH, Jeong WI, et al: Signal transducer and activator of transcription 3-mediated CD133 up-regulation contributes to promotion of hepatocellular carcinoma. Hepatology 62: 1160-1173, 2015.

27. Mak AB, Nixon AM and Moffat J: The mixed lineage leukemia (MLL) fusion-associated gene AF4 promotes CD133 transcription. Cancer Res 72: 1929-1934, 2012.

28. Iida H, Suzuki M, Goitsuka R and Ueno H: Hypoxia induces CD133 expression in human lung cancer cells by up-regulation of OCT3/4 and SOX2. Int J Oncol 40: 71-79, 2012.

29. Zhang L, Li H, Ge C, Li M, Zhao FY, Hou HL, Zhu MX, Tian H, Zhang LX, Chen TY, et al: Inhibitory effects of transcription factor Ikaros on the expression of liver cancer stem cell marker CD133 in hepatocellular carcinoma. Oncotarget 5: 10621-10635, 2014.

30. Ohnishi S, Maehara O, Nakagawa K, Kameya A, Otaki K, Fujita H, Higashi R, Takagi K, Asaka M, Sakamoto N, et al: hypoxia-inducible factors activate CD133 promoter through ETS family transcription factors. PLoS One 8: e66255, 2013.

31. Min KJ, So KA, Ouh YT, Hong JH and Lee JK: The effects of DNA methylation and epigenetic factors on the expression of CD133 in ovarian cancers. J Ovarian Res 5: 28, 2012.

32. Vogelstein B, Lane D and Levine AJ: Surfing the p53 network. Nature 408: 307-310, 2000.

33. Puca F, Colamaio M, Federico A, Gemei M, Tosti N, Bastos AU, Del Vecchio L, Pece S, Battista S and Fusco A: HMGA1 silencing restores normal stem cell characteristics in colon cancer stem cells by increasing p53 levels. Oncotarget 5: 3234-3245, 2014. 
34. Zeilstra J, Joosten SP, Vermeulen L, Koster J, Medema JP, Versteeg R, Spaargaren M and Pals ST: CD44 expression in intestinal epithelium and colorectal cancer is independent of p53 status. PLoS One 8: e72849, 2013

35. Park EK, Lee JC, Park JW, Bang SY, Yi SA, Kim BK, Park JH, Kwon SH, You JS, Nam SW, et al: Transcriptional repression of cancer stem cell marker CD133 by tumor suppressor p53. Cell Death Dis 6: e1964, 2015.

36. Shmelkov SV, Butler JM, Hooper AT, Hormigo A, Kushner J, Milde T, St Clair R, Baljevic M, White I, Jin DK, et al: CD133 expression is not restricted to stem cells and both $\mathrm{CD} 133^{+}$and CD133- metastatic colon cancer cells initiate tumors. J Clin Invest 118: 2111-2120, 2008.

37. Kawamoto H, Yuasa T, Kubota Y, Seita M, Sasamoto H, Shahid JM, Hayashi T, Nakahara H, Hassan R, Iwamuro M, et al: Characteristics of CD133(+) human colon cancer SW620 cells. Cell Transplant 19: 857-864, 2010.

38. Rassouli FB, Matin MM and Saeinasab M: Cancer stem cells in human digestive tract malignancies. Tumour Biol 37: 7-21, 2016.

39. Smeenk L, van Heeringen SJ, Koeppel M, van Driel MA Bartels SJ, Akkers RC, Denissov S, Stunnenberg HG and Lohrum M: Characterization of genome-wide p53-binding sites upon stress response. Nucleic Acids Res 36: 3639-3654, 2008

40. Hoh J, Jin S, Parrado T, Edington J, Levine AJ and Ott J: The p53MH algorithm and its application in detecting p53-responsive genes. Proc Natl Acad Sci USA 99: 8467-8472, 2002.

41. Gowrisankar S and Jegga AG: Regression based predictor for p53 transactivation. BMC Bioinformatics 10: 215, 2009.

42. Ma B, Pan Y, Zheng J, Levine AJ and Nussinov R: Sequence analysis of p53 response-elements suggests multiple binding modes of the p53 tetramer to DNA targets. Nucleic Acids Res 35: 2986-3001, 2007.

43. Veprintsev DB and Fersht AR: Algorithm for prediction of tumour suppressor p53 affinity for binding sites in DNA. Nucleic Acids Res 36: 1589-1598, 2008.
44. Tebaldi T, Zaccara S, Alessandrini F, Bisio A, Ciribilli Y and Inga A: Whole-genome cartography of p53 response elements ranked on transactivation potential. BMC Genomics 16: 464, 2015.

45. Botcheva $\mathrm{K}$ and McCorkle SR: Cell context dependent p53 genome-wide binding patterns and enrichment at repeats. PLoS One 9: e113492, 2014.

46. Williams K, Christensen J, Rappsilber J, Nielsen AL, Johansen JV and Helin K: The histone lysine demethylase JMJD3/KDM6B is recruited to $\mathrm{p} 53$ bound promoters and enhancer elements in a p53 dependent manner. PLoS One 9: e96545, 2014.

47. Zhao Q, Zhou H, Liu Q, Cao Y, Wang G, Hu A, Ruan L, Wang S, Bo Q, Chen W, et al: Prognostic value of the expression of cancer stem cell-related markers CD133 and CD44 in hepatocellular carcinoma: From patients to patient-derived tumor xenograft models. Oncotarget 7: 47431-47443, 2016.

48. Thanan R, Pairojkul C, Pinlaor S, Khuntikeo N, Wongkham C, Sripa B, Ma N, Vaeteewoottacharn K, Furukawa A, Kobayashi $\mathrm{H}$, et al: Inflammation-related DNA damage and expression of CD133 and Oct $3 / 4$ in cholangiocarcinoma patients with poor prognosis. Free Radic Biol Med 65: 1464-1472, 2013.

49. Le H, Zeng F, Xu L, Liu X and Huang Y: The role of CD133 expression in the carcinogenesis and prognosis of patients with lung cancer. Mol Med Rep 8: 1511-1518, 2013.

50. Zhuang HW, Mo TT, Hou WJ, Xiong GX, Zhu XL, Fu QL and Wen WP: Biological characteristics of CD133(+) cells in nasopharyngeal carcinoma. Oncol Rep 30: 57-63, 2013.

51. Wen L, Chen XZ, Yang K, Chen ZX, Zhang B, Chen JP, Zhou ZG, Mo XM and Hu JK: Prognostic value of cancer stem cell marker CD133 expression in gastric cancer: A systematic review. PLoS One 8: e59154, 2013.

52. Kim K, Ro JY, Kim S and Cho YM: Expression of stem-cell markers OCT-4 and CD133: Important prognostic factors in papillary renal cell carcinoma. Human Pathol 43: 2109-2116, 2012. 